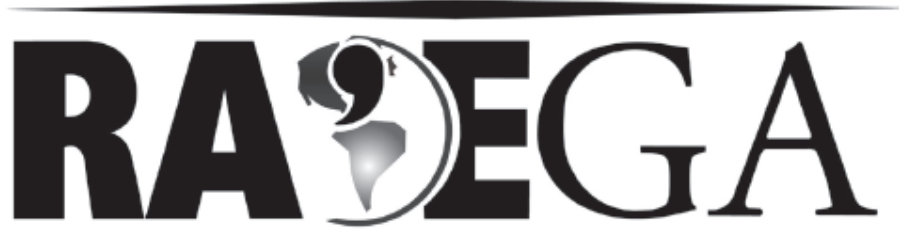

O ESPAÇO GEOGRÁFICO EM ANÁLISE

\title{
POLÍTICAS PÚBLICAS, CULTURAS POPULARES E PATRIMÔNIO CULTURAL IMATERIAL: MEIOS E ALTERNATIVAS
}

\author{
PUBLIC POLICIES, POPULAR CULTURE AND \\ INTANGIBLE CULTURAL HERITAGE: MEANS AND \\ ALTERNATIVES
}

\author{
Alessandra Fonseca Leal ${ }^{1}$ \\ Erika Adriana Leal ${ }^{2}$
}

\section{RESUMO}

Este trabalho é resultado da pesquisa Cultura Popular e Patrimônio Cultural, o olhar de dentro para fora: uma análise sobre a gestão da cultura popular pelos 'fazedores' de cultura ${ }^{3}$, e tem como objetivo refletir sobre as políticas públicas no Brasil, tendo em vista a organização do Estado e a estrutura que ele oferece às culturas populares e ao patrimônio cultural imaterial. Veremos o desenrolar da legislação e os desdobramentos políticos entre cultura popular e patrimônio cultural, que são mais do que parecidos, repetidos. O que podemos perceber, olhando para toda a trajetória de implementações de discursos, leis, decretos, portarias é que o principal motivador das várias gestões seria a preocupação com a construção da identidade nacional, e de que ela poderia representar entre os esforços no desenvolvimento econômico e, sobretudo, social do país.

PALAVRAS-CHAVE: cultura popular; patrimônio cultural imaterial; políticas públicas; gestão cultural.

\footnotetext{
${ }^{1}$ Integrante do OPARÁ - Grupo de Estudos e Pesquisas sobre Comunidades Tradicionais no rio São Francisco. Doutoranda no Programa de Pós-Graduação em Geografia da Universidade Federal da UFU. Bolsista CAPES ale.leal@msn.com

2 Integrante do OPARÁ - Grupo de Estudos e Pesquisas sobre Comunidades Tradicionais no rio São Francisco. Graduada em História pela Universidade Estadual de Montes Claros. erikadrileal@gmail.com

${ }^{3}$ A pesquisa foi premiada pela FUNARTE com a Bolsa de Produção Crítica em Conhecimentos Tradicionais e Culturas Populares em 2010/2011 e gerou a dissertação Semear cultura, Cultivar culturas populares, Colher patrimônios: a gestão social da cultura popular às margens do Rio São Francisco no Norte de Minas Gerais.
} 


\section{ABSTRACT}

This paper presents the findings of the research "Popular Culture and Cultural Heritage, the look from inside out: An analysis of the management of popular culture for the 'makers' of culture", and aims to reflect on the policies in Brazil, considering that the organization of the State and the opportunities it offers to popular culture and to intangible cultural heritage. We have seen that historically the unfolding political developments of legislation between popular culture and cultural heritage are more than similar, repeated. What we can see, looking at the whole trajectory of implementations of speeches, laws, decrees, ordinances is that the main motivator of the various administrations would be a concern with the construction of national identity, and that it could represent between efforts in the country's economic and, above all, social development.

KEYWORDS: popular culture; intangible cultural heritage; public policy; cultural management.

Todo caminho da gente é resvaloso. Mas também, cair não prejudica demais - a gente levanta, a gente sobe, a gente volta!... o correr da vida embrulha tudo, a vida é assim: esquenta e esfria, aperta e daí afrouxa, sossega e depois desinquieta.

A vida quer da gente é coragem!"

João Guimarães Rosa - Grande Sertão Veredas

\section{Dizendo Políticas Culturais na Cultura}

As políticas culturais para a cultura popular no Brasil acompanham de certo modo o mesmo movimento de desenvolvimento ocorrido com o patrimônio cultural imaterial. A mesma corrente que mobilizou a Semana de Arte Moderna em 1922 em prol da cultura popular e do patrimônio cultural, norteou também outras alternativas de apoio a tais artes e ofícios.

Essa iniciativa é consideravelmente conduzida pelas estruturas políticas organizadas por Getúlio Vargas em toda a década de 30.

No contexto que aqui nos interessa, Vargas, nos primeiros anos da década de 1930, inicia a política de criação de autarquias e conselhos nacionais que cuidariam de setores específicos (como nos casos dos Conselhos Nacionais de Estatística e Geografia), ou de produtos considerados economicamente importantes [...] (ALMEIDA, 2003. p. 114) 
O enfoque da política institucional de Vargas estava longe de se dedicar às artes e à cultura. Com o cunho desenvolvimentista e preocupado com 0 crescimento econômico, as políticas culturais eram uma ponta da aresta construída aos tropeços por esforços e iniciativas individuais, como foi o caso de Mário de Andrade.

Sensibilizado pelo movimento modernista, entretanto, ainda com o entendimento destorcido do que deveras seria a cultura, é criado em 1931, pelo Decreto № 19.850 o Conselho Nacional de Educação do Governo Federal.

(...) cujos objetivos eram "elevar o nível da cultura brasileira" e, entre as atribuições, promover e estimular iniciativas em benefício da cultura nacional; em outras palavras, acreditavase que a população brasileira possuía um baixo nível cultural originado pela falta de acesso e conhecimento da produção artística e cultural erudita, cabendo ao governo reverter tal situação. (CALABRE, 2009. p. 17)

O decreto, da mesma forma como ocorreu no campo do patrimônio cultural, não mobilizou reais ações que promovessem ou incentivassem 0 desenvolvimento das artes no país. A iniciativa retorna a 1935 com a experiência no estado de São Paulo, através das medidas de Mário de Andrade.

Mário de Andrade assumiu a direção do Departamento de Cultura do estado de São Paulo, responsável pela política patrimonial, e do Departamento de Expansão Cultural. "As atividades das divisões desse departamento estavam todas articuladas entre si, buscando potencializar os resultados obtidos por meio da criação de políticas públicas para a área da cultural" (CALABRE, 2009. p. 19)

Como resultado, houve a construção de museus, congressos de estudos sobre cultura e cultura popular, implementação de bibliotecas públicas e municipais. Investimento em projetos de qualificação e profissionalização de profissionais e técnicos em biblioteconomia.

O cinema foi contemplado em 1932 com o Decreto $n^{\circ}$ 21.240, que acentuava a obrigatoriedade da participação da cultura popular e a apresentação de filmes brasileiros de curta-metragem. Apesar de todos os problemas do decreto, como limitações e coibições da censura, ele estimulava 
a produção nacional, incluindo a possibilidade de participação de culturas não prestigiadas na época como a cultura popular.

A lei do curta-metragem - ou lei do short, como se chamou na época - representou para os produtores a possibilidade de manter a continuidade de seu trabalho. Em poucos meses, algumas centenas de curtas estavam sendo distribuídos pelo país, num destemido flagrante à argumentação dos exibidores de que uma lei de obrigatoriedade era absurda, pois não havia produção a ser exibida. (CALABRE, 2009. p. 29)

Claro que em tempos de ditaduras, os problemas não eram poucos e a intervenção direta do Estado era constante. Assim, o mesmo movimento que incentivava também podava e limitava.

Com o teatro e o rádio não foi diferente. Ele foi agraciado com a criação da Comissão Nacional do Teatro em setembro de 1936, que deveria iniciar programas de estudos e atividades teatrais.

Em 21 de dezembro de 1937, foi promulgado o Decreto Lei $n^{\circ}$ 92 que criava o Serviço Nacional de Teatro (SNT). No texto introdutório, o decreto considerava o teatro como "uma das expressões da cultura nacional, e a sua finalidade é, essencialmente, a elevação e a edificação espiritual do povo" sendo o SNT destinado a "animar o desenvolvimento e 0 aprimoramento do teatro brasileiro". (CALABRE, 2009. p. 29)

O rádio recebe em 1934 o Departamento de Propaganda e Difusão Cultural, que teria como objetivo o incentivo da divulgação das artes pela radiodifusão e a 'elevação do espírito das massas". Entretanto, mais que do que teatro e o cinema, o rádio sofreu censuras fortíssimas em tempos de ditaduras. Os programas eram fiscalizados e deveriam ter os mesmos horários e difusão por todo o território nacional. Transformando-se em mais do que uma promoção da arte e da cultura uma forma de manipulação e doutrinamento do povo. Ressalvas à parte, as emissoras de radio conquistam o território nacional.

Com a demissão de Mário de Andrade em 1938, já lembrada aqui, o cenário das políticas culturais perdem espaço e permanece em sono dormente até 1945.

Em 1946, com o fim da Segunda Guerra Mundial e do período militar, o país explode numa busca acelerada pelo desenvolvimento industrial. Livres da 
censura, rádio, cinema, teatro e literatura promovem juntos um aumento significativo de produções e criações.

Até 1960 pouca foi a intervenção do Estado para com a promoção da cultura. Sua atuação limitou-se a outorgas de decretos e regulamentações que fortaleciam o plano de gestão cultural já implementado pelo governo de Getúlio Vargas. No entanto, a liberdade de expressão foi suficiente para promover sozinha uma explosão da diversidade de produção cultural no país. Um crescimento incentivado pelo desenvolvimento industrial e pela dinâmica do capitalismo, que agita o mercado de serviços e bens e estimula o consumo constante. "No caso do rádio, em 1945 foram criadas 111 emissoras; em 1946, foram 136 e em 1950, surgiram 300 novas emissoras, ou seja, a taxa de crescimento aumentou em quase $200 \%$ em cinco anos." No cinema não foi diferente, "segundo o IBGE, entre 1949 e 1950 a metragem de filmagens nacionais dobrou, passando de 181.218 para 357.565 metros". (CALABRE, 2009. p. 45-46)

Nota-se, entretanto, que o teatro e a literatura tiveram neste período ainda pouco espaço, mesmo com todo o incentivo de um mercado capitalista em expansão. Isto forçava o governo a conceder esporádicos auxílios financeiros para sua viabilização. O que nos leva a confirmar que não existia um real planejamento que alicerçasse base para a promoção das artes e da cultura.

Sobre a cultura popular, continuavam existindo apenas as iniciativas políticas pensadas e colocadas em prática por Mário de Andrade. Nesse período, o próprio governo não definia qual o entendimento que teria sobre 0 tema, que ora pendia para a compreensão do patrimônio como bem cultural, como alicerce da identidade nacional, ora como cultura de um "povo colonizado, que deveria ser suplantando, ao mesmo tempo em que a urbanização e a industrialização deveriam construir um novo povo brasileiro, uma nova cultura popular" (CALABRE, 2009. p. 50)

Em 1955, por meio do Decreto no 37.608 , é criado o ISEB - Instituto Superior de Estudos Brasileiros. Em seu documento de base "folclore e cultura tinham significados antagônicos: o primeiro significava tradição e o segundo, 
transformação. Logo, a finalidade da cultura popular era fornecer consciência ao povo e ser um elemento transformador." (CALABRE, 2009. p. 53). No ISEB as principais práticas eram estudos e pesquisas, nada havendo de ações destinadas a incentivos ou de atuação conjunta ao povo.

No entanto, o ISEB juntou-se aos movimentos de cultura popular que surgiram no começo da década de 60 , e que trataram de reinventar o próprio significado da cultura popular. Ela deixa de ser algo criado e praticado por um povo 'subalterno' e 'alienado'. E passa a representar a face de consciência crítica e resistência do povo. Ao mesmo tempo, cultura popular passa a ser um campo ativo de diálogo entre estudantes, profissionais, militantes políticos revolucionários e "artistas comprometidos com o povo". Estas pessoas e grupos de ação educativa e cultural atuavam através de movimentos culturais, de instituições estudantis - em que se destaca a União Nacional dos Estudantes UNE - partidos políticos de esquerda e outras agremiações.

Este é o tempo do Movimento de Educação de Base - MEB, do teatro do oprimido, de Augusto Boal, do cinema novo e de várias outras iniciativas culturais que buscavam, para além das políticas públicas, realizar um trabalho de mobilização cultural em todo o Brasil. E, através deste movimento, um trabalho de transformação "da realidade política e social do Brasil". Aqui o nome de Paulo Freire e de tantos outros "militantes de cultura popular" devem ser lembrados. Lembremos também que em Recife, em 1962 realiza-se o primeiro Encontro Nacional de Movimentos de Cultura Popular.

Fora o que se fez em e entre circuitos militantes e independentes, o que promoveu e possibilitou o desenvolvimento das expressões artísticas e da cultura neste período foram os investimentos privados e iniciativas independentes. Ou seja, o mercado e a indústria provocaram o nascimento de uma indústria cultural que viabilizou ações e criações múltiplas. Indústria que financia a Bossa Nova, o Cinema Novo e a poesia concreta nos fins dos anos 50.

Em 1991 é homologado, pela Lei № 8.313, de 23 de dezembro, o PRONAC - Programa Nacional de Apoio à Cultura. Popularmente conhecido como Lei Rouanet, em reconhecimento ao criador, o sociólogo Sérgio Paulo 
Rouanet. O Programa buscava fomentar alternativas em que se mesclavam a intervenção pública e a privada para o financiamento de projetos que, dentre outros critérios:

a. contribuam para facilitar os meios para um livre acesso às fontes da cultura e o pleno exercício dos direitos culturais;

b. apoiassem, valorizassem e difundissem o conjunto das manifestações culturais e seus respectivos criadores;

c. salvaguardem a sobrevivência e o florescimento dos modos de criar, lazer e viver da sociedade brasileira;

d. preservassem os bens materiais e imateriais do patrimônio cultural e histórico brasileiro.

Para serem contempladas as propostas deveriam ser previamente aprovadas pela Comissão Nacional de Incentivos à Cultura - CNIC, do Ministério da Cultura.

O Programa possuía três mecanismos de estímulo a projetos culturais: o FNC - Fundo Nacional da Cultura, o FICART - Fundo de Investimento Cultural e Artístico e o MECENATO - Incentivo a projetos culturais. Cada um possuía suas formas específicas de seleção e incentivo financeiro. O primeiro (FNC) é constituído principalmente de recursos advindos das loterias federais, do Tesouro Nacional, do Fundos de Desenvolvimento Regional e doações, além de saldos ou devoluções oriundos de projetos de Mecenato, saldos de exercícios anteriores e resgate de empréstimos. O MECENATO possibilitava o financiamento de projetos por instituições ou pessoas que se interessarem, oferecendo a estas reduções no imposto de renda. Normalmente as propostas eram submetidas a editais de empresas patrocinadoras, como o Banco do Brasil, a CEMIG, o Banco do Nordeste, etc. O FICART previa, sem qualquer intervenção do Ministério da Cultura, a composição de fundos por meio da isenção de imposto de renda e de operações de crédito, câmbio e seguro. A implementação do FICART está em estudos pela Secretária de Apoio à Cultura do Ministério da Cultura.

"A lei Rouanet" gerou um novo impulso às produções culturais, ainda que nos primeiros anos tivesse havido diversas dificuldades de 
implementação." (CALABRE, 2009. p. 111) . Ela veio corrigir alguns problemas que as legislações anteriores possuíam desde o entendimento do que vinha a ser "culturas", até a forma de viabilizar sua produção.

Em 1993 acontece em Brasília a I Conferência Nacional de Cultura, organizada pela Organização Não Governamental Cult. O encontro mobilizou a sociedade civil, profissionais e artistas num debate de permitiu o fomento de novas práticas e atividades mais intensas, junto às políticas culturais.

Em 1995 o Ministério da Cultura, já no governo Fernando Henrique Cardoso, promoveu "círculos de reuniões entre especialistas franceses e brasileiros, denominados 'Encontros Malrax', sob o tema 'Cultura, Estado e Sociedade: França e Brasil. Neles novamente debatem-se a falta de recursos e os problemas das políticas culturais. Dentre eles a centralização dos recursos na região sudeste e obscuridade dos processos de seleção e de concessão dos mesmos.

As concessões do Governo Federal para com a aprovação dos projetos inscritos restringiam-se à mera conferência de enquadramento do pedido às artes permitidas pela legislação. A escolha definitiva de quem receberia de fato o recurso ficariam à cargo das empresas que destinariam a porcentagem de seus impostos devidos. Isto fez com que a escolha dos projetos se baseassem basicamente nos interesses de mercado para ampla divulgação e marketing cultural. "O que o governo terminou fazendo foi liberar recursos públicos para serem aplicados sob a ótica do interesse empresarial" (CALABRE, 2009. p. 117). Se por um lado isto incentiva a produção, por outro desprestigia as artes, subordinando os critérios de valor artístico e cultural ao interesse de promoção da imagem de empresas comerciais.

Entre 1995 e 2002 as políticas culturais, apesar de haverem galgado passos significativos para permitir o acesso do povo a ferramentas de produção cultural, ainda não se haviam alicerçado numa gestão planejada. Leis e decretos eram promulgados à partir da necessidade de solução imediata de problemas advindos do PRONAC, sem contudo, firmar bases e projeções para saídas a dificuldades futuras tanto para o Estado, para empresa quanto para o povo. 
Em 2003, com a gestão de Luiz Inácio Lula da Silva e a entrada de Gilberto Gil no Ministério da Cultura, ocorreram profundas transformações e rearranjos dentro da lógica de funcionando do Ministério da Cultura, com o objetivo agilizar o sistema e reformular uma política de incentivos, antes, centrada basicamente na Lei Rouanet. Com isso, o ministério dissolveu e criou novas secretarias, sendo elas: Secretaria de Articulação Institucionais, a Secretaria de Políticas Culturais, a Secretaria de Fomento e Incentivo à Cultura, a Secretaria de Programas e Projetos Culturais, a Secretaria do Audiovisual e a Secretaria de Identidade e Diversidade Cultural.

Com o objetivo de rearranjar internamente os mecanismos de financiamento, promoveu consultas públicas e seminários "Cultura para todos". Reuniões e encontros com secretarias estaduais e municipais. Os participantes receberam duas perguntas para responder, e do diálogo ao redor de suas respostas poderiam sair as reformulações ministeriais.

Quais os principais entraves para o acesso ao financiamento público federal de cultura (Lei Rouanet e Lei do Audiovisual)? Que mecanismos devem ser adotados para garantir a transparência, a democratização e a descentralização do financiamento público da cultura?

A avaliação mais geral foi a de que o mecanismo necessitava ser reformulado; porém, havia uma série de problemas que poderiam ser solucionados por meio de portarias ministeriais, divulgação mais sistemática da lei e capacitação de produtores e de gestores nas mais diversas regiões do país. Uma outra conclusão foi a importância do mecanismo dentro de determinadas áreas da produção cultural, o que apontaria para a necessidade de que o projeto de reformulação fosse realizado de maneira a não paralisar os processos em curso. (CALABRE, 2009. p. 123).

Desde 2003, e a partir dos seminários e congressos realizados, a Lei Rouanet vem sendo re-pensada, tendo em visto os problemas e desencontros em meio aos quais a sociedade civil e o poder de Estado não conseguiam estabelecer diálogo. Como conseqüência, em 2010 a Lei é reformulada, sendo implementada pela primeira vez em 2010.

O PRONAC transforma-se em PRÓCULTURA - Programa Nacional de Fomento e Incentivo à Cultura, aprovada pelo Projeto de Lei no 6722/2010, que passa a ter como objetivo central ampliar os recursos da cultura e diversificar 
os mecanismos de financiamento, de forma a desenvolver uma verdadeira Economia da Cultura no Brasil

Os mecanismos de financiamento são dinamizados; critérios e objetivos são estabelecidos para que haja avaliação clara e justa dos projetos inscritos; parcerias entre Estado e sociedade civil são aprofundadas; estímulos à cooperações entre federação, estados e municípios são estimulados e estabelecidos. Uma das principais preocupações de toda esta reformulação foi evitar a intermediação entre recurso e destinatário, com maior participação da sociedade.

O PRÓCULTURA conserva algumas características do PRONAC, como o FNC e o FICART, e reformular outros, ficando estruturado e divido em quatro fundos:

O FNC - Fundo Nacional da Cultura passa a ser dividido em oito fundos setoriais.

1. Artes Visuais;

2. das Artes Cênicas;

3. da Música;

4. do Acesso e Diversidade;

5. do Patrimônio e Memória;

6. do Livro, Leitura, Literatura e Humanidades,

7. de Ações Transversais e Equalização; e

8. de Incentivo à Inovação do Audiovisual.

Buscou-se, nesse novo modelo, a atenuação da burocracia para a concessão de incentivos, ao lado de novas formas de fomento a serem implementadas, como a concessão de bolsas e prêmios, em que a prestação de contas é simplificada, de modo que haja preocupação com os resultados apresentados ao final dos projetos. O que passa a contar agora é a iniciativa e o retorno que o projeto trará para a arte, a cultura e a cultura popular, seja sob a forma de pensamento e pesquisa estruturada, seja como atividades diretas como apresentações de shows, teatros e simbólicas. 
É mantido o Incentivo Fiscal a Projetos Culturais, que se conserva de certa forma parecida com antiga forma de captação do PRONAC por meio de dedução no imposto de renda, de pessoas jurídicas e físicas. O sistema mantém as características essenciais do antigo PRONAC.

É relevante também a atuação do FICART - Fundo de Investimento Cultural e Artístico; através do qual os investidores associados tornam-se sócios de projetos culturais. Os investimentos poderão ser retornáveis ou não. No primeiro caso deve ser garantida a participação do Fundo Nacional de Cultura, quando do retorno comercial do projeto cultural. No segundo, o financiamento fica "condicionado à gratuidade ou comprovada redução nos valores dos produtos ou serviços culturais resultantes do projeto cultural, bem como à abrangência da circulação dos produtos ou serviços em pelo menos quatro regiões do País". (PROJETO DE LEI n 6722/2010).

É criado ainda o Vale-Cultura - Programa de Cultura do Trabalhador, oficializado pelo Projeto de Lei 221 de 2009, que oferece ao trabalhador de carteira assinada um vale, concedido por meio de cartão magnético, de $R \$$ 50,00 (cinqüenta reais) por mês, a ser investido em entretenimentos culturais, como passeio em cinemas, shows, teatros e aquisição de livros. $O$ incentivo viabiliza a abertura de cinemas em bairros populares e a produção cinematográfica. As empresas que optarem por disponibilizar o vale ao trabalhador terá dedução de 1\% (um por cento) no imposto de renda. Mas, independente da empresa, os trabalhadores poderão adquirir o cartão.

Em dezembro de 2004 o Ministério da Cultura assina parceria com o Instituto Brasileiro de Geografia - IBGE para que fosse incluído um bloco de informações básicas sobre cultura na pesquisa de informações básicas municipais. As informações subsidiaram planejamentos na elaboração Plano Nacional de Cultura e de programas e projetos promovidos pelo MinC.

Em 2005 acontece a I Conferência Nacional de Cultura, que assim como - Seminário "Cultura para todos", promovia a reflexão nacional sobre o contexto das políticas culturais. As informações da conferência, somadas às do seminário, fundamentaram as ações para programação e implementação do 
novo Plano Nacional de Cultura, instituído pela Ementa Constitucional № 48 de $1^{\circ}$ de agosto de 2005.

- O Plano Nacional de Cultura tinha como diretriz:

- Defesa e valorização do patrimônio cultural brasileiro;

- Produção, promoção e difusão de bens culturais;

- Formação de pessoal qualificado para gestão da cultura em suas múltiplas dimensões;

- Democratização do acesso aos bens da cultura;

- Valorização da diversidade étnica e regional. Ementa Constitucional no 48, 2005

Outra estratégia foi a implementação do Sistema Nacional de Cultura $S N C$, que facilitou a gestão do Plano Nacional de Cultura e permitiu o diálogo interno entre as secretarias. O SNC foi e segue sendo importante não só na gestão do patrimônio cultural. Ele permitiu, ainda, a comunicação entre as políticas, o banco de dados e de informações que possuíam. As políticas de patrimônio cultural encontravam-se de certo modo dissociadas e afastadas das demais atividades das secretarias culturais. Como mediador desse problema foi criado também o Conselho Nacional de Política Cultural - CNPC, em 24 de agosto de 2005.

Em 2007, vimos que o Ministério da Cultura implementa o Programa Mais Cultura. Este está divido em três extensões básicas, todas com foco sobre a participação da sociedade civil e jurídica: Cultura e Cidadania (que organiza o Cultura Viva); Cultura e Cidades; e a Cultura e Economia.

As ações e iniciativas do Programa são divulgadas por meio de Editais publicados no Diário da União, e conseqüentemente no site do MinC. São sempre destinados a projetos e pessoas (físicas e jurídicas) com natureza e fins culturais.

A extensão Cultura e Cidadania promove o Programa Cultura Viva, que por sua vez promove os Pontos de Cultura. O Programa Cultura Viva é a iniciativa que mais se aproxima das culturas populares. Dele partiram encontros com grupos de cultura popular, promovidas ainda quando da presença de Gilberto Gil no Ministério da Cultura. Encontros que incutiram nos autores/atores a consciência da importância de seus atos para o país. Veremos 
isto mais de perto quando estudarmos o caso do Grupo de Folia de Reis Garça Branca Peito de Aço de Pirapora;

O Cultura Viva tem como objetivos:

- Ampliar e garantir acesso aos meios de fruição, produção e difusão cultural

- Identificar parceiros e promover pactos com atores sociais governamentais e não-governamentais, nacionais e estrangeiros, visando um desenvolvimento humano sustentável, no qual a cultura seja forma de construção e expressão da identidade nacional

- Incorporar referências simbólicas e linguagens artísticas no processo de construção da cidadania, ampliando a capacidade de apropriação criativa do patrimônio cultural pelas comunidades e pela sociedade brasileira

- Potencializar energias sociais e culturais, dando vazão à dinâmica própria das comunidades e entrelaçando ações e suportes dirigidos ao desenvolvimento de uma cultura cooperativa, solidária e transformadora

- Fomentar uma rede horizontal de "transformação, de invenção, de fazer e refazer, no sentido da geração de uma teia de significações que envolva a todos"

- Estimular a exploração, o uso e a apropriação dos códigos de diferentes meios e linguagens artísticas e lúdicas nos processos educacionais, bem como a utilização de museus, centros culturais e espaços públicos em diferentes situações de aprendizagem e desenvolvendo uma reflexão crítica sobre a realidade em que os cidadãos se inserem

- Promover a cultura enquanto expressão e representação simbólica, direito e economia. (MINC, noticiário, 2010).

Por meio dele, os autores/atores de cultura popular, e mesmo seus intermediários podem acessar os recursos do PRÓCULTURA, ora por meio do Fundo Nacional de Cultura, ora meio do Incentivo Fiscal a Projetos Culturais. $O$ edital é que determinará a fonte do fundo.

O Ponto de Cultura "é a ação prioritária e o ponto de articulações das demais atividades do Programa Cultura Viva". "Os Pontos de Cultura são espaços permanentes de experimentação, encanto, transformação e magia," segundo Luiz Inácio Lula da Silva. "O Ponto de Cultura é "uma espécie de 'doin' antropológico, massageando pontos vitais, mas momentaneamente desprezados ou adormecidos, do corpo cultural do País", de acordo com Gilberto Gil. (MINC, Noticiário, 2010) 
Os Pontos de Cultura oferecem um recurso significativo a organizações da sociedade civil (OSCIPS, Associações, Instituições de Estudos e Pesquisas), que trabalhem diretamente em prol do resgate e da valorização da cultura e da cultura popular num local.

O Ponto de Cultura não tem um modelo único, nem de instalações físicas, nem de programação ou atividade. Um aspecto comum a todos é a transversalidade da cultura e a gestão compartilhada entre poder público e comunidade. (...) Quando firmado o convênio com o MinC, o Ponto de Cultura recebe a quantia de $\mathrm{R} \$ 185$ mil, em cinco parcelas semestrais, para investir conforme projeto apresentado. Parte do incentivo recebido na primeira parcela, no valor mínimo de $R \$ 20$ mil, para aquisição de equipamento multimídia em software livre (os programas serão oferecidos pela coordenação), composto por microcomputador, mini-estúdio para gravar CD, câmera digital, ilha de edição e o que mais for importante para o Ponto de Cultura. (MINC, noticiário, 2010).

A idéia é que os Pontos de Cultura fortifique as ações que já acontecem nas comunidades, de modo a fortalecer também a identidade dos que ali estão envolvidos. Já foram implementados 1460 pontos de cultura em todo o país.

As extensões de Cultura e Cidades e a Cultura e Economia promovem ainda outros programas que se acoplam ou não ao Cultura Viva, de forma a empoderar o programa e as iniciativas do FNC.

\section{Refletindo sobre as Políticas Culturais no Brasil}

Em 30 de julho de 2008, o então ministro Gilberto Gil pede demissão do seu cargo e volta a dedicar-se à sua carreira de cantor. Deixa no ministério sua marca de transformações e atualizações no sistema.

Para Isaura Botelho (2007), na gestão Gil, depois de muitas idas e vindas do ministério, teve um processo de discussão e reordenação do papel do Estado na área cultural com tentativas de recomposição de orçamento, melhor distribuição dos poucos recursos. A pesquisadora destaca ainda 0 investimento "na recuperação de um conceito abrangente de cultura", o fato de "considerar como fundamental a articulação entre cultura e cidadania" e o alerta para "o peso da cultura em termos da economia global do país". (CALABRE, 2009. p. 125) 
É difícil tecer comentários sobre os acontecimentos e as conseqüências das políticas culturais que vêem se processando nos últimos anos. Os processos e projetos estão em suas primeiras experiências, de modo que não é possível a visualização e a análise dos reais resultados dos mesmos. É necessário um distanciamento significativo para que críticas e abordagens possam ser elaboradas de forma impessoal.

O que podemos perceber, olhando para toda a trajetória de implementação de discursos, leis, decretos, portarias é que o principal motivador das várias gestões seria a preocupação com a construção da identidade nacional, e de que ela poderia representar entre os esforços no desenvolvimento econômico e, sobretudo, social do país.

Em todo o processo de desenvolvimento que vivemos a cultura não é tomada como algo essencial ou importante em nenhum momento. As poucas ações que acontecem são conseqüências de atitudes de interesses pequenos grupos. A preocupação central é com a integração nacional, e são utilizados todos os meios para a manipulação midiática e a subordinação do povo a interesses divididos entre a preservação de hegemonias políticas e os ganhos do capital, inclusive o aplicado sobre a cultura.

Tanto durante o Governo Militar quanto nos anos que se seguem, de 1970 a 2002, mantém-se, com variantes, uma atitude conservadora e desconexa de iniciativas efetivas de atuação e pensamento cultural. Entre 1960 e 1990, com as trocas de gestão públicas, algumas transformações acontecem e provocam atualizações nas formas de pensamento e ação pública, sem, contudo, transformarem significativamente a gestão de políticas culturais vigentes. A cultura popular sequer foi lembrada, para além dos limites da política do patrimônio cultural imaterial.

O discurso identitário se perde em meio ao essencialismo autoritário e conservador dos anos 1930/40 e 1960/70. E toda a gestão da cultura passa a ser pautada pela lógica do mercado globalizado. O retorno à democracia nos anos 1990 faz fronteira com o fortalecimento no Brasil do ideário neoliberal, que os governos FHC assumem. A conseqüência para o campo cultural é a ratificação da política de incentivos fiscais iniciadas no governo Sarney. Uma 
vez posto em xeque o lugar unificador e integrador da identidade nacional, parece prevalecer o discurso liberal da diversidade, onde todos são iguais perante o mercado.

Com o governo Lula, tem-se uma reavaliação do que seria a identidade acional brasileira que aponta para o pluralismo e a incorporação de expressões culturais historicamente excluídas. A diversidade não resulta mais em uma síntese, pelo contrário, é o pólo identitário que cede à diversidade e se multiplica em identidades. Há, por sua vez, a crítica à concepção mercadológica da cultura e a cobrança do papel fundamental do Estado como elaborador e executor de políticas culturais. (BARBALHO, 2007.)

Talvez o mais revolucionário em todo este acontecer tenha sido as inovações que vêm acontecendo desde 2003, quando a prioridade passa a ser o permitir às culturas latentes que falem por si mesmas, em suas diversidades, para, a partir daí, se fazerem compreendidas como Patrimônio Cultural e como o patrimônio que é a identidade do povo e, através dele, do país.

Inovações que, esperamos, desdobrem-se em inovações que permitam que as culturas, principalmente a culturas populares, sejam compreendidas em conjunto com seus autores/atores, através de um respeito e um novo entendimento dos atos de significação intuitivos, tratados agora de forma harmônica e respeitosa.

Diga-se que mesmo com todos os problemas existentes, o rearranjo exercido na administração de Gilberto Gil, foi de tal forma significativo que não apenas ampliou debates e discussões, alterando opiniões e abordagens políticas e culturais em todo o país, como logrou incorporar junto aos próprios autores-atores um embrião de um re-significar de suas identidades. Cultura popular e culturas populares, foliões, rabequeiros, benzedeiros, não são agora vistos como formas culturais marginais, mas como exemplos de cultura viva. $\mathrm{E}$ são eles assim entendidos por eles mesmos.

A partir daí, eles estão reivindicando diretamente os seus direitos e valores. A abertura do MinC permitiu o aflorar e o desenrolar de relações e rearranjos internos e externos dos atores-autores individuais e coletivos de culturas patrimoniais. Claro, este acontecimento, como tudo que é novo, aponta sempre para dois lados. Um positivo, com a chegada do novo, de incorporação 
do povo numa dinâmica multicultural e global. E outro negativo, quando este acontecer ameaça afastar, como já comentamos anteriormente, os criadores/atores de culturas populares de seus sujeitos e contextos sociais e afetivos de origem.

Vale fazer saber é que é com a implementação do Plano de Políticas Culturais, do Sistema Nacional de Cultura Popular e do Programa Cultura Viva que foliões como Seo Carlos ${ }^{4}$ conseguem ter acesso ao Ministério da Cultura diretamente. Mesmo que seja apenas para uma conversa formal e dissociada de recurso financeiro direto.

Ao mesmo tempo, começam a ressurgir em todo o Brasil diferentes fóruns da sociedade brasileira, como um contraponto às iniciativas governamentais e empresariais. O Fórum Social Mundial ${ }^{5}$, os encontros de movimentos sociais, O Encontro dos Povos do Cerrado, são bons exemplos.

Mais importante do que o que se passa como iniciativa pública, são os encontros, as oficinas, os festivais etc., promovidos por instituições populares de cultura, ou por instituições da sociedade civil (com ou sem a presença e o patrocínio estado), por todo o país, e envolvendo todas as categorias culturais e sociais, desde povos indígenas até operários.

Temos o exemplo, em termos de Norte de Minas, do Encontro dos Povos do Cerrado. Ele se realiza através do esforço conjugado da UNIMONTES, de prefeituras locais, de ONGS. Mas entende-se que a presença principal é a de segmentos das comunidades populares do Cerrado. Temos ainda encontros propriamente populares, como o de dos Vazanteiros, dos Povos da Floresta e tantos outros. Tais encontros unem vozes e entendimentos para aprofundamento de suas questões, e para juntos tornarem públicas, ouvidas e atendidas necessidades e reformulações. Alguns deles geram importantes documentos e manifestos.

Dos encontros, grupos ganham força política e institucional. Estruturamse em organizações não- governamentais, ou em associações para mediarem

\footnotetext{
${ }^{4}$ Folião de Santos Reis do Terno de Folia Garça Branca Peito de Aço de Pirapora que cedeu informações e entrevistas à esta pesquisa.

5 "O Fórum Mundial Social é um espaço de debate democrático de idéias, aprofundamento da reflexão, formulação de propostas, troca de experiências e articulação de movimentos sociais, redes, ONGS e outras organizações da sociedade civil que se opõem ao neoliberalismo e ao domínio do mundo pelo capital e por qualquer forma de imperialismo." (FMS, NOTICIÁRIO, 2010)
} 
voz e vez junto ao Estado, e para tornarem eficientes em suas utilizações as ferramentas construídas para eles. Ali eles trocam experiências e compartem descobertas, tanto quanto aos conhecimentos e saberes que geram e socializam, quanto às inovações provocadas pelos seus rearranjos na gestão de suas criações e manifestações.

Das trocas e das redes sociais e culturais que se originam delas, nasce por todo o Brasil um movimento de ampliação de valores comunitários, harmônicos e de respeito aos seus próprios saberes e fazeres: seus atos de significação intuitivos e seus conhecimentos tradicionais. Juntos, viabilizam ações, mesmo que pequenas e restritas ao alcance dos grupos locais. Ações de divulgação de seus modos de vida, seus valores e visões de mundo que, não raro opõem-se às práticas empresariais, mercantis e francamente capitalistas vigentes no mundo e largamente planejadas pelo governo brasileiro.

Voltemos ao Fórum Social Mundial, pois ele é um exemplo significativo. O Fórum proporciona o encontro e a mobilização de redes nas mais diversas áreas de atuação social, econômica e cultural, gerando e facilitando articulações e incentivando e viabilizando ações conjuntas concretas. Uma experiência fecunda e proveitosa de uma comunidade barranqueira do Rio São Francisco, passa a ser conhecida por uma comunidade tradicional amazônica. As trocas se fazem presentes e, nelas, temos o fluir das inovações, aproveitando arranjos antigos num contexto que, fundamentado no saber/fazer tradicional, promove também inovações que, inseridas no capitalismo, propõem novos caminhos. $O$ acontecer é lento, mas efetivo e fecundo.

Vemos isso claramente nas feiras de artesanato cultural e feiras de produtos naturais artesanalmente trabalhados e de produtos naturais, além de feiras de produtos orgânicos e outras mais. São comunidades e grupos que resgatam um modo de vida de um ontem nem tão distante, mas que, respeita e é coerente com os atos intuitivos sobre os quais atuam.

Com isso são cada vez mais freqüentes as iniciativas de comunidades e grupos em suas trocas solidárias e na adoção de práticas solidárias de economia e produção. Novidades e inovações promovem sempre rearranjos 
internos e externos. Essas iniciativas de teor interativo e intra-comunidades estão permanentemente se enfrentando com estratégias externas, isto é, vinda de poderes e de propagandas de empresas ou do próprio governo. O resultado disto é que, não raro, estas pressões externas provoquem conflitos e novos arranjos nas relações também internas às comunidades. Elas, lenta, mas efetivamente se reorganizam, transformam e devolvem ao que vem de fora e é imposto, criações que mesmo com a marca do "de fora". Reproduzem ainda a sua própria lógica, que inclui, agora, o "de fora" e o "de dentro". O que chega de fora e vai provocar na cultura popular o que Canclini, uma vez mais, chamará de hibridização. Culturas populares Não serão jamais as mesmas, e para isto basta a chegada da televisão ou de uma iniciativa de política pública na comunidade. Mas é através do que muda ao se hibridizar que um momento de atos de significação peculiares ao povo preservarão a sua originalidade e a sua identidade.

E os agentes e agências externas, por sua vez, receberão de contextos de culturas populares, como em um espelho em que mesmo a contragosto vêem a sua face refletida no fazer do outro, influências vindas "de dentro" e "de baixo", e que provocarão revisões e re-arranjos nas próprias políticas públicas. O sempre transformar e criar em meio a alianças e conflitos, a arranjos e rearranjos, a apropriações e promoções, a expropriações e gestos de ajuda de proteção.

\section{BIBLIOGRAFIA}

ABREU, Regina. \& CHAGAS, Mário. (org.) Memória e Patrimônio: ensaios contemporâneos. Rio de Janeiro: Lamparina, 2009.

ALMEIDA, Lúcio Flávio Rodrigues de. A ilusão de desenvolvimento: nacionalismo e dominação burguesa nos anos JK. Florianópolis: Ed da UFSC. 2006. p.147-230.

ALMEIDA, Roberto Schmidt de. A Estruturação de Tecnoburocracia do Planejamento Territorial no Brasil. In IN: Terra Brasílis - Revista de História do Pensamento Geográfico no Brasil. Rio de Janeiro. 2002-2003 Anos III-IV, N. 4-5. p. 113-135. 
BARBALHO, Alexandre. Políticas Culturais no Brasil: identidade e diversidade em diferença. In Anais do III ENECULT - Encontro de Estudos Multidisciplinares em Cultura. Faculdade de Comunicação da Universidade Federal da Bahia, em 23 a 25 de maio de 2007.

BRANDÃO, Carlos Rodrigues. Cultura Popular e Educação: salto para o futuro. In: SILVA, René Marc da Costa. Cultura Popular e Educação. Brasília: Ministério da Educação, Secretária de Educação a distância, 2008. p. 25-100.

- O Saber, 0 cantar e 0 viver do povo. São José dos Campos: Centro de Estudos da Cultura Popular. Fundação Cultural Cassiano Ricardo. Cadernos de Foclore. 2009B.

.O que é folclore. São Paulo: Brasiliense, 2007.

. A cultura na Rua. Campinas-SP: Papirus, 1989.

. A Educação como Cultura. Campinas: Mercado das Letras, 2002.

- Notas de aula da Disciplina Tópicos Especiais em Geografia: Cultura Popular e Memória Social, ministrada pelo Professor Carlos Rodrigues Brandão no segundo semestre de 2010.

BURKE, Peter. Cultura Popular na Idade Moderna. São Paulo: Companhia das Letras, 1999.

CALABRE, Lia. Políticas Culturais no Brasil: dos anos 1930 ao século XXI. Rio de Janeiro: Editora FGV, 2009.

CANCLINI, Néstor Garcia. Culturas híbridas: estratégias para entrar e sair da modernidade. São Paulo: EDUSP, 2003.

CARTA DE ATENAS. Escritório Internacional dos Museus, outubro de 1931. In: Instituto do Patrimônio Histórico e Artístico Nacional. Disponível em: <http:// portal.iphan.gov.b $\mathrm{r} /$ portal $/$ montarPaginaSecao. do? $\mathrm{id}=12372 \&$ sigla=Legislacao\&retorno=paginaLe gislacao>. Acessado em: 29/01/2007.

CARTA DE FORTALEZA. Fortaleza, 14 de novembro de 1997. n: Instituto do Patrimônio Histórico e Artístico Nacional. Disponível em: $<$ http://portal.iphan.gov.br/portal/montarPaginaSecao.do?id=12372\&sigla=

Legislacao\&retorno=paginaLegislacao $>$. Acessado em: 31/01/2007.

CARTA DE NARA. Nara, 6 de novembro de 1994. In: Instituto do Patrimônio Histórico e Artístico Nacional. Disponível em: $<$ http://portal.iphan.gov.br/portal/montarPaginaSecao.do?id=12372\&sigla =Legislacao\&retorno=paginaLegislacao $>$. Acessado em: 31 jan. 2007. 
CARTA DO FOLCLORE BRASILEIRO. Salvador: VIII Congresso Brasileiro de Folclore, 12 a 16 de dezembro de 1995.

CASTRIOTA, Leonardo Barci. Patrimônio Cultural: conceitos, políticas e instrumentos. São Paulo: AnnaBlume, 2009

CONSTITUIÇÃO FEDERAL DE 1988. Governo Federal. In. Senado Federal. disponível em: <http://www.planalto.gov.br/CCIVIL_03/Constituicao/Constitui\%C3\%A7ao.htm>. Acessado em: 08 fev.2007.

CONVENÇÃO SOBRE A SALVAGUARDA DO PATRIMÔNIO CULTURAL IMATERIAL. Paris, 29 de setembro a 17 de outubro de 2003. In: Instituto do Patrimônio Histórico e Artístico Nacional. Disponível e $m$ : $<$ http://portal.ipha.gov.br/portal/montarPaginaSecao.do?id=12372\&sigla=Legisl acao\&retorno=paginaLegislacao >. Acessado em: 31 janeiro de 2007.

CONVENÇÃO SOBRE A PROTEÇÃO DO PATRIMÔNIO MUNDIAL CULTURAL E NATURAL. Paris, 16 de novembro de 1972. In: Instituto do Patrimônio Histórico e Artístico Nacional. Disponível em: http:/135/portal.iphan.gov.br/portal/montarPaginaSecao.do?id=12372\&sigla=Le gislacao\&

retorno=paginaLegislacao. Acessado em: 29/01/2007.

DECLARAÇÃO UNIVERSAL SOBRE A DIVERSIDADE CULTURAL. 11 de setembro de 2001. União das Nações Unidas para a Educação, Cultura e Ciência. Disponível em: www.unesco.org.br. Acessado em: 05/01/2007.

DECRETO № 3.551. 05 de agosto de 2000. Presidência da República. Disponível em http://www.planalto.gov.br/ccivil 03/decreto/D3551.htm. Acessado em: 22/06/2011.

EAGLETON, Terry. A idéia de cultural. São Paulo: Editora Unesp, 2005.

FÓRUM SOCIAL MUNDIAL. Noticiário: O que é o Fórum Social Mundial?. In: www.forumsocialmundial.org.br/main.php?id menu=19\&cd language=1, disponível em 23 de julho de 2007.

INSTITUTO DO PATRIMÔNIO HISTÓRICO E ARTÍSTICO NACIONAL. Os Sambas, as Rodas, os Bumbas, os Meus e os Bois: a trajetória da salvaguarda do patrimônio cultural imaterial no Brasil. Brasília, 2006.

Disponível

Relatório "Ofício das Paneleiras de Goiabeiras". IPHAN:BRASÍLIA http://portal.jphan.gov.br/portal/montarDetalheConteudo.do?id=12568\&sigla=ln stitucional\&retorno=detalhelnstitucional Acessado em 16/10/2006B

Relatório “Arte Kusiwa -
IPHAN:BRASÍLIA


http://portal.iphan.gov.br/portal/montarDetalheConteudo.do?id=12568\&sigla=In stitucional\&retorno=detalhelnstitucional Acessado em 16/10/2006C

Paisagem Cultural. (cartilha) Brasília, 2009

Noticiário: Patrimônio Cultural Imaterial. In: www.iphan.gov.br/bcrE/pages/indexE.jsf, acessado em 27 de novembro de 2010.

LE PATRIMOINE CULTUREL IMMATERIÉL: lês enjeux, lês problématiques, lês pratiques. Internationale de Imaginaire, Nouvelle Série, 17. BABEL: Maison dês Cultures Du Monde, 2004.

NOTICIÁRIO. Prefeitura Municipal de Pirapora, 2010. Disponível em www.pirapora.mg.gov.br/index.php\%3Fpage\%3Dpaginas\%26idPagina\%3D3+hi stória+de+pirapora\&cd=2\&hl=pt-BR\&ct=clnk\&gl=br\&client=firefox-a. . Acessado em 08 de janeiro de 2011.

NOTICIÁRIO. Velho Chico. Net, 2006. Disponível em http://velhochico.net/index arquivos/Page\%20953H.htm. Acessado em 10 de janeiro de 2010.

OLIVEIRA, Vânia Dolores Estevam de. Campanha de Defesa do Folclore Brasileiro: estratégias e redes de resistência na construção da memória da cultura popular brasileira. In: Encontro Regional da Associação Nacional de História do Rio de Janeiro: Memória e Patrimônio. Rio de Janeiro, 19 a 23 de julho de 2010.

ORTIZ, Renato. Cultura Popular: românticos e folcloristas. São Paulo: PUC-SP, 1985.

PRESIDÊNCIA DA REPÚBLICA. Decreto-lei № 3.551/00. Brasília, 04 de Agosto de 2000. Governo Federal. In: Senado Federal. Disponível em: http://www6.senado.gov.br/legislacao/ListaPublicacoes.action?id=174182.

Acessado em: 30/01/2007.

PRESIDÊNCIA DA REPÚBLICA. Ementa Constitucional no 48. Brasília, 10 de agosto de 2005. Governo Federal. In: Presidência da República Federativa do Brasil.

Disponível em: http://www.planalto.gov.br/ccivil 03/constituicao/Emendas/Emc/emc48.htm. Acessado em 30/12/2010

RECOMENDAÇÃO DE PARIS. Paris, 19 de novembro de 1964. In: nstituto do Patrimônio Histórico e Artístico Nacional. Disponível em: http://portal.iphan.gov.br/portal/montarPaginaSecao.do?id=12372\&sigla=Legis| acao\&retorno=paginaLegislacao. Acessado em: 29/01/2007.

RECOMENDAÇÃO SOBRE A CONSERVAÇÃO DOS BENS CULTURAIS AMEAÇADOS PELA EXECUÇÃO DE OBRASS PÚBLICAS OU PRIVADAS. Paris, 15 de outubro a 20 de novembro de 1968. In: Instituto do Patrimônio 
Histórico e Artístico Nacional. Disponível em: http://portal.iphan.gov.br/portal/montarPaginaSecao.do?id=12372\&sigla=Legis| acao\&retorno=paginaLegislacao. Acessado em: 29/01/2007.

RECOMENDAÇÃO SOBRE A SALVAGUARDA DA CULTURA TRADICIONAL E POPULAR. Paris, 15 de novembro de 1989. In: Instituto do Patrimônio Histórico e Artístico Nacional. Disponível em: http://portal.jphan.gov.br/portal/montarPaginaSecao.do?id=12372\&sigla=Legisl acao\&retorno=paginaLegislacao. Acessado em: 30/01/2007.

REDE DE TECNOLOGIA SOCIAL. Noticiário: Brasília sedia o Encontro Nacional dos Povos do Cerrado. In: www.rts.org.br/noticias/destaque-4, disponível em 13 de setembro de 2009.

RODRIGUES, Luciene, OLIVEIRA, Marcos F. (org.). Formação social e econômica do Norte de Minas. Montes Claros: UNIMONTES, 2000.

ROSA, João Guimarães. Grande Sertão Veredas. Rio de Janeiro: Nova Fronteira, 2001.

SANCHES, Sydney Lemeira. 0 patrimônio cultural imaterial e a Propriedade Intelectual: harmonia ou conflito de interesses. Centro de Pesquisa e Documentação de História contemporânea do Brasil - CPDOC. Fundação Getúlio Vargas.

SANTOS, Márcio. Rio São Francisco: patrimônio cultural e natural. Belo Horizonte: Assembléia Legislativa de Minas Gerais, 2003.

SERVIÇO DO PATRIMÔNIO HISTÓRICO E ARTÍSTICO NACIONAL, FUNDAÇÃO NACIONAL PRÓ-MEMÓRIA. Proteção e Revitalização do Patrimônio Cultural do Brasil: uma trajetória. SPHAN: Brasília. 1980. Publicação no 31 . 